\title{
LA ECONOMÍA POLÍTICA DE LA SANIDAD COLONIAL EN GUINEA ECUATORIAL
}

\author{
BENITA SAMPEDRO VIZCAYA ${ }^{200^{*}}$ \\ Hofstra University (New York)
}

\begin{abstract}
Resumen: Las intervenciones médicas desempeñaron un papel importante en la colonización de África. La morbilidad y la enfermedad fueron una preocupación constante de los médicos, militares, científicos, políticos, colonos y miembros de las órdenes religiosas. El papel de la medicina y la ciencia en la arquitectura de la administración colonial está ligado, por lo tanto, de manera inextricable, a la legitimización de la ocupación y a los proyectos de 'misión civilizadora'. El desarrollo de un discurso biomédico como parte del proceso colonizador de España en los Territorios españoles del Golfo de Guinea contribuyó desde el primer momento a la construcción de lo que entendemos por "África", y del cuerpo africano como locus de la enfermedad, necesitado de reparación social y sujeto de conocimiento y observación por parte del estado colonial represor. Las tecnologías biomédicas sirvieron como instrumentos de consolidación de las estructuras coloniales, en particular durante la primera mitad del siglo XX. El presente ensayo responde a las siguientes preguntas: ¿cómo se gestó y se aplicó, y qué especificidades caracterizó, el conocimiento biomédico español? ¿Cómo se puso en circulación en la Guinea colonial y en la España metropolitana? ¿Hasta qué punto contribuyó a solidificar la arquitectura del poder colonial? En los regímenes dictatoriales postcoloniales, la salud y el miedo se fusionan con frecuencia bajo una misma categoría, para actuar como estratagemas de represión socio-política. La patología sistémica de las dictaduras incorpora, como parte de su etiología, manifestaciones clínicas
\end{abstract}

200 * Benita Sampedro Vizcaya Agradece la financiación recibida, a través de una Beca Hispanex del Ministerio de Educación, Cultura y Deportes de Espańa, en la convocatoria del 2013, para la realización del trabajo de archivo y la investigación para este proyecto. Es profesora titular de estudios coloniales en la Universidad de Hofstra (Nueva York). Este ensayo es una de las contribuciones que realiza como miembro del proyecto de investigación HAR2012-34599, del Ministerio de Economía y Competitividad de España, titulado "Lo que sabemos, ignoramos, inventamos y deformamos acerca del pasado y el presente de Guinea Ecuatorial. Revisión crítica multidisciplinar y nuevas vías de investigación”. Su correo electrónico es Benita.sampedro@hofstra.edu 
que incluyen la obstrucción de valores democráticos y el fomento de las desigualdades socio-económicas. La reapropiación de determinados aspectos del aparato biomédico colonial es, por consiguiente, instrumental para problematizar cuestiones de duración, de reproducción y de repetición en los regímenes actuales.

Palabras clave: Medicina colonial, morbilidad, mortalidad, enfermedad, tecnologías biomédicas

AвSTRACT: Medical interventions played a pivotal role in the European colonization of Africa. Morbidity and disease were a constant preoccupation for colonial medical officers, the military, scientists, politicians, settlers, and members of the religious orders alike. The role of medicine and science in the architecture of the colonial administration is, therefore, inextricably intertwined with the legitimization of occupation, and the projects of the 'civilizing mission'. The development of a biomedical discourse as part of the Spanish colonial enterprise in Equatorial Guinea contributed, from a very early stage, to the construction of what we understand by "Africa", and of the African body as a site of disease, requiring social repair, and as a subject of knowledge and observation in a repressive colonial state. Biomedical technologies served as powerful instruments of consolidation of colonial structures, particularly during the first half of the twentieth century. The present essay addresses the following questions: How was this biomedical knowledge produced and implemented, and what specificities characterized it? How was it brought into circulation both in colonial Guinea and in metropolitan Spain? To what extent these biomedical technologies contributed to the solidification of the architecture of colonial power? Finally, often in postcolonial regimes health and fear are conflated under one same category, and act as stratagems of socio-political repression. The systemic pathology of dictatorships incorporates, as part of its etiology, clinical manifestations that include the obstruction of democratic values, and the fostering of socio-economic inequalities. The re-appropriation of concrete aspects of the colonial biomedical apparatus is therefore useful to problematize questions of duration, reproduction and repetition under the current regimes.

KeYwords: Colonial Medicine, Morbidity, Mortality, Disease, Biomedical Technologies 
Perdido para siempre el inmenso poderío Colonial en América y Oceanía, sólo nos resta una pequeña porción de territorio africano, tan menospreciada por nosotros, desde los gobernantes hasta los pobres diablos de la Nación, como codiciada por las potencias extranjeras (...) pero del mismo modo que un organismo robusto, amenazado de muerte, cuenta con poderosas energías que sabiamente encauzadas le han de llevar a la curación, así la potente España, hoy en el período pre-agónico, puede revivir y levantarse lozana, si una mano enérgica detiene su desmembramiento y una inteligencia directriz la vigoriza. África, rico porvenir de la agotada Europa, es hoy la única vía de expansión para la pobre España.

Pablo Ferrer Piera, 1900, 5-6.

Este epígrafe puede servir como punto de partida idóneo para ilustrar la persistencia de la metáfora de la enfermedad, que imbrica los conceptos de salud e imperialismo, el cuerpo y la nación, y marca de manera prominente el discurso oficial, durante varias décadas, en las relaciones entre España y África, entre finales del siglo XIX y la primera mitad del XX. La metáfora subraya la centralidad de la intervención médica en el proceso de expansión territorial. La cita procede del prólogo del libro de Pablo Ferrer Piera, Fernando Poo y sus dependencias. Descripción, producciones y estado sanitario, publicado en Barcelona en el año 1900, aunque podría haber sido fácilmente extraída de muchos otros tratados políticos, geográficos o económicos sobre las colonias españolas diseminados en esa misma década. Ferrer Piera fue uno de los médicos, con especialización en bacteriología, enfermedades infecciosas y lo que por entonces se llamaba medicina tropical, que participó en una expedición a los Territorios españoles del Golfo de Guinea en los albores del siglo XX, y el citado libro constituía el informe oficial de dicha expedición. En el prólogo mencionado -dirigido al "Excelentísimo Marqués de Comillas", Claudio López Bru- une la condición moribunda de la nación española a las preocupaciones por la salud local. El tratado incluye varios capítulos extensos sobre el paludismo, su biología, etiología, análisis, tratamientos y profilaxis. Tras un dilatado recorrido por la isla de Fernando Poo, con paradas en distintos puntos (San Carlos, Batete, Concepción, o Basilé), y aportando en ocasiones inesperadas observaciones etnográficas sobre las prácticas médicas de los bubi, ${ }^{201}$ prosigue viaje hacia Cabo San Juan y las islas de Elobey y Corisco,

201 Sobre el conocimiento médico de los bubis concluye: "Practican la Medicina y Cirujía con bastante sentido común. Sumamente parcos en la medicina interna, se contentan con administrar purgantes, estimulantes y diaforéticos. Usan una planta sumamente aromática en la pulmonía, otra para las hematurias y otra para el paludismo, Las demás, repito, son de 
para cerrar cada uno de los capítulos con un informe sobre el estado sanitario de la conscripción geográfica correspondiente. El libro concluye con una valoración final positiva con respecto a las condiciones sanitarias de la colonia, junto con una serie de recomendaciones médicas a través de las cuales "estas hermosas regiones africanas" podrían llegar a ser "prósperas y felices, levantando con ellas el prestigio de esta infortunada España” (1900, 205).

No cabe duda de que Ferrer Piera, como la mayoría de los científicos y políticos de su generación en España, conocía el discurso, de amplia difusión en Europa por aquellos años, del político conservador británico Lord Salisbury, pronunciado en el Albert Hall de Londres en mayo de 1898, y que llegó a designarse como el discurso de las "naciones moribundas" [the dying nations speech]. ${ }^{202}$ En el mismo, Lord Salisbury, aplicando principios darwinistas, dividía las naciones en dos categorías claramente definidas, naciones con vida o moribundas. Década tras década, argumentaba, las naciones moribundas se convertirían en más débiles y más pobres, mientras que las naciones con vida irían progresivamente incorporando el territorio de las moribundas. ${ }^{203}$ Este discurso, pronunciado en el momento de mayor apogeo de la expansión británica y europea en África, articulaba una posición ampliamente compartida en la Europa de finales del siglo XIX:

El imperialismo se percibía como un proceso biológico que, de acuerdo con las leyes de la naturaleza, daría lugar o a la 'curación' o al 'desmembramiento' de los estados débiles, que se equiparaban a los 'enfermos' en proceso de descomposición, listos para la autopsia (Morton, 2005, 371).

El discurso tocó, de seguro, un nervio sensible en el pensamiento político español tras la llamada 'pérdida de las últimas colonias', justo en la coyuntura

aplicación general y las administran con cautela, por conocer las propiedades tóxicas de algunas (...) El tratamiento de las fracturas en nada varía del usado por nosotros (...) Practican asimismo la sangría en la mediana basílica” (Ferrer Piera, 1900, 116-8).

202 Para más datos sobre el Primer Ministro conservador Robert Cecil (1886-92), también conocido como Lord Salisbury, con respecto a sus visiones sobre el imperio y la trascendencia de su discurso impregnado de conceptos darwinistas ver, entre otros, Adam David Morton (2005) y Andrew Roberts (2013).

203 "En su discurso dividía el mundo en naciones con vida y naciones moribundas, y la mayoría de los españoles entendió perfectamente bien que, para el estadista inglés, ellos pertenecían a la segunda categoría" (Storm 2004, 5). Ésta, y todas las traducciones del inglés en el presente ensayo, son mías. Para la aplicación de esa metáfora de la nación y la enfermedad, aplicada a un período ligeramente posterior, ver Francisco Javier Martínez Antonio, "El imperio enfermizo" (2009). 
de retirada, y ante la amarga realidad de lo que se percibía como ganancias vergonzosamente modestas en el reparto territorial de África. De manera uniforme, los científicos y estrategas españoles de estos años y aún de las décadas posteriores, al igual que sus contrapartes en otras naciones europeas, asociaron la salud del proyecto colonial en África con los retos específicos de la colonización y la explotación. Luis Nájera Angulo, ${ }^{204}$ funcionario de la administración sanitaria, firme defensor de la expansión del sistema de salud pública a las colonias y del aumento del presupuesto, afirmaba en torno a 1944, en un popular programa de radio en España que "el siglo XX será el siglo de la colonización de África (...) Toda empresa colonizadora es fundamentalmente y ante todo una empresa de salud pública" $(1944,302)$. Citaba como referentes a diversos militares africanistas franceses, entre ellos Joseph Gallieni, cuando afirmaban, "Dame un médico por cada cien soldados y mis hombres no perderán ni una gota de sangre". Refiriéndose a otro general francés de la época, aseguraba que "Cuando llegó a Marruecos, hacía treinta años, pidió médicos más que soldados, porque un buen médico valía por diez batallones", decía (1944, 303-304). De esta manera Nájera Ángulo subrayaba el papel fundamental que las intervenciones sanitarias habían desempeñado en la colonización de África, ideas que ya venía articulando con respecto a los Territorios españoles desde su estancia como médico del servicio sanitario colonial entre 1929 y $1930:^{205}$

El problema sanitario es, no cabe dudarlo, la cuestión más importante de cuantas lleva consigo la penetración y colonización de un país (...) En sus montes seculares, junto a la casi inagotable riqueza de sus primorosas maderas y en sus llanuras de exuberante fertilidad, se escondían los enemigos invisibles que diezmaban a los soldados y dispersaban a los colonos o los hacían perecer, víctimas del paludismo, de la tripanosomiasis y de la fiebre amarilla. Allí los ejércitos de soldados apenas si servían para otra cosa que para agravar la situación; allí los ejércitos habían de ser de higienistas y de sanitarios $(1931,15)$.

204 Autor de influyentes publicaciones en bacteriología y parasitología, entre ellas Los territorios españoles en el Golfo de Guinea. Estado sanitario actual y su influencia sobre el desarroIlo de la colonización (1932), ayudó a fundar, y luego presidió, durante la época de la II República, la Asociación de médicos coloniales.

205 Ocupó el cargo de director de la hipnosería de Santa Isabel y supervisó el establecimiento de otro centro de aislamiento para los enfermos de tripanosomiasis en Elobey Chico. Parte de su experiencia en Elobey Chico aparece recogida como uno de los episodios narrados en su artículo "El paludismo náutico" (1944). 
Pero además, según Nájera Ángulo, la explotación efectiva de los recursos de la colonia es directamente proporcional a la inversión e intervención sanitarias: "es muy legítimo, y a mi juicio altamente meritorio que, por quienes puedan hacerlo, se desee aprovechar las inmensas riquezas forestales de nuestra colonia del Muni, contribuyendo a mejorar la balanza comercial de Espańa y a realizar la alta misión que se nos tiene confiada”, pero es impensable, advierte, "proyectar siquiera una empresa de explotación colonial sin contar con una partida de gastos sanitarios" $(1931,16){ }^{206}$

La morbilidad y la enfermedad fueron, en efecto, preocupaciones constantes, y en ocasiones obsesivas, para los médicos y científicos de la colonia, así como para los administradores, políticos, militares, colonos y miembros de las órdenes religiosas destinados al continente. En los territorios españoles, como en el resto de contextos coloniales, "la medicina occidental se presentó, en general, como uno de los pocos beneficios indudables del imperialismo europeo" (Anderson, 1998, 522). Es por ello que, para el mismo Nájera Ángulo, la sanidad colonial no solo ejerce un poder incontestable sobre el colonizado sino que opera, literalmente, "milagros":

El indígena que ha visto una vez cómo un enfermo de mawara (pian) se ha curado en cuarenta y ocho horas con una sola inyección es un esclavo nuestro (...) lo mismo ocurre con el enfermo que, sometido al oportuno tratamiento, contempla la expulsión de gran número de parásitos intestinales o la notable y rápida mejoría de un tripanosomiásico en período de letargia o hipnosis (1931, 17-18).

Una oportuna intervención sanitaria es crucial para impedir "la ruina definitiva de nuestra última colonia”, pronostica el mismo funcionario. ${ }^{207}$ Sin embargo,

$206 \mathrm{Al}$ respecto del apogeo de la Medicina tropical, y del surgimiento de los institutos de salud pública, Nájera Morrondo reitera el vínculo de la disciplina con "el colonialismo y la necesidad de estudiar y tratar de resolver problemas ligados a la penetración y a la explotación de las tierras africanas", al tiempo que apunta que "En nuestro país, prácticamente no se despierta la necesidad y el interés hasta la penetración en los bosques de Guinea, con las explotaciones forestales" $(2006,590)$.

207 Ante una grave crisis de tripanosomiasis sufrida en Fernando Poo en el año 1932, y que se extiende hacia Bata, Nájara Ángulo, muy crítico con la Dirección del Servicio Sanitario colonial, presentó un informe, en nombre de la Asociación de médicos coloniales que presidía, que concluía así: "Esta asociación, deseando evitar la responsabilidad en que pudiera incurrir por silenciar hechos de tal gravedad, solicita del Gobierno la adopción de las medidas adecuadas para resolver esta lamentable situación sanitaria, impidiendo así la ruina definitiva de nuestra última colonia". Como resultado del mismo, se abrió un "Expediente 
como nos advierte Franz Fanon (que también era médico) en su conocido ensayo sobre medicina y colonialismo, "por lo general, los nativos no interpretaron las estadísticas sobre las mejoras sanitarias como avances en la lucha contra la enfermedad, sino como prueba adicional del control irreversible de las fuerzas de ocupación sobre sus propios territorios" $(1978,229)$. El papel de la medicina y de la ciencia en la arquitectura de la administración colonial está, por lo tanto, ligado de manera inextricable a la legitimación de la ocupación y, como ya señalara Rosa María Medina Doménech, justificado como parte del proyecto de la misión civilizadora $(2002,392)$. Los investigadores de historia de la medicina colonial son conscientes de estas consideraciones a la hora de trazar las asociaciones inherentes entre salud e imperio, desde la "producción colonial de la enfermedad" a "la medicina y la salud pública como discursos técnicos del colonialismo" (Anderson, 1998: 523).

El desarrollo de un discurso biomédico más o menos sistemático, como parte de la empresa colonial en los Territorios españoles del Golfo de Guinea, ha contribuido sin duda, desde una fase temprana, a la construcción del imaginario sobre África, del cuerpo africano como un locus de la enfermedad necesitado de reparación social, y a la vez como sujeto de conocimiento y observación por parte del estado colonial represor. Como apunta Ruth Mayer en su libro Artificial Africas, aunque progresivamente se han ido superando los terrores asociados al territorio y las proyecciones coloniales negativas, "ningún otro continente ha adquirido nunca tantas connotaciones de peligro como el africano" $(2002,257)$. La propuesta que se intenta avanzar es que las tecnologías biomédicas, es decir, la investigación y las ciencias aplicadas a la salud humana, las enfermedades y, con la llegada de los años 50, la psicología, así como la economía política de la salud, funcionaron como instrumentos claves del pensamiento y las prácticas coloniales en los Territorios españoles del Golfo de Guinea desde finales del siglo XIX hasta la independencia, si bien con diversas estrategias operativas y variados niveles de intensidad según las zonas y la época. Es pertinente observar entonces cómo se generó, y cómo se aplicó, el conocimiento biomédico colonial, a menudo presentado en forma de catálogos de la mortalidad, la morbilidad, la enfermedad, la degeneración y la ruina, y observar también a través de qué

incoado para esclarecer las denuncias formuladas..." (Archivo General de la Administración, África, Sección 15, Fondo 4, Caja 81-06336). 
medios se puso en circulación, principalmente en forma de ciencia popular, en la Espańa metropolitana. ${ }^{208}$

Los discursos y prácticas biomédicos absorbieron e implementaron muchos de los elementos intrínsecamente coloniales de la medicina: no es gran revelación el señalar aquí que privilegiaron categorías físicas o relacionales tales como el género, la raza, la etnia, la edad, o el parentesco, todas ellas marcadores clásicos de la diferencia y de la otredad. Es importante advertir también que el propósito último de la medicina colonial no fue siempre (o no fue necesariamente) la salud en sí misma de la población local. Fue, como ya hemos comenzado a observar, un componente pragmático, al servicio de la administración colonial, estrechamente ligado a proyectos militares primero, y luego civiles o misioneros, según las atribuciones asignadas. De hecho, el concepto militar de higiene es un punto crítico de la transferencia, mientras que el sufrimiento, el dolor y el pecado son elementos consustanciales a los discursos médicos misioneros. Por otra parte, la aplicación de la medicina europea a sociedades no europeas ha tenido siempre un impacto incuestionable, aunque no siempre fácilmente cuantificable, en el proceso de dislocación y de desarticulación de saberes y de prácticas curativas locales. En este sentido, es enormemente enriquecedor estudiar las respuestas de la población local a imposiciones biomédicas y sanitarias coloniales concretas, muchas de las cuales incluyeron, sin lugar a dudas, prácticas y modos de análisis profundamente humillantes y deshumanizantes, o simplemente carentes de efectividad sustancial. Sin embargo, y a la inversa, en línea con lo que señala Shula Marks (1997), aunque este enfoque no se limita en sentido estricto a la economía política de la gestión de la salud y la enfermedad coloniales, la reflexión sirve también para revelar que la historia de la medicina en las colonias es, por lo general, tan ilustrativa de la manera en que se ejerció el poder como de las limitaciones mismas de ese poder colonial, de sus proyectos y de sus discursos.

Resultaría críticamente improductivo a estas alturas preguntar qué es colonial (qué define lo colonial) en la medicina occidental aplicada al contexto africano, pero parece razonable y hasta necesario, sin embargo, reformular la pregunta e indagar qué es lo que es distintivo en su práctica en un contexto colonial

208 Para un estudio general sobre la fundación de los institutos de salud pública y su vínculo con los proyectos coloniales ver Rafael Nájera Morrondo (2006); y, para la popularización del conocimiento científico sobre las colonias africanas a través de una red estatal de expertos, asociados al Instituto de Estudios Africanos del Consejo Superior de Investigaciones Científicas, ver Cécile Stephanie Stehrenberger (2014). 
específico, y en qué manera las teorías biomédicas y sus aplicaciones contribuyeron a solidificar, de manera determinante, la arquitectura del poder colonial. En esta coyuntura, puede ser útil vincular el trabajo sobre la economía política de la salud con la crítica de la medicina como discurso colonial y su impacto en el cuerpo del colonizado, incluyendo la mirada de la cámara (la fotografía y el cine) en el análisis del imaginario médico colonial, a través de un acercamiento a las ciencias biomédicas desde sus formas de representación. En un sentido más abstracto, que además nos conecta con el presente, el objetivo sería, como señala Ann Laura Stoler, "volver a centrarse en el tejido conectivo que sigue enlazando la potencialidad humana con un medio degradado, y las individualidades degradadas con los desechos materiales de los proyectos imperiales" $(2008,193)$. Sin embargo esto nos lleva a importantes consideraciones sobre la durabilidad de los procesos:

Lo que está en cuestión es la vida política del detritus imperial, la longevidad de las estructuras de dominación, y el ritmo desigual al que los pueblos se liberan del orden colonial (...) La pregunta tiene una carga importante: ¿En qué manera persisten las formaciones imperiales en sus desechos materiales, en sus paisajes de ruina y a través de la ruina social de la vida de los pueblos? (Stoler 2008, 193-194).209

Sin lugar a duda, una de las primeras preocupaciones de los administradores españoles en Guinea desde el siglo XIX fueron la salud y la higiene públicas, como parte integral del proyecto militar. De Granda Orive estudió recientemente la sanidad militar en Fernando Poo durante el gobierno de los brigadieres (18591869), dando cuenta, por ejemplo, de las principales epidemias que afectaron a la isla en ese período, y Alejandro Belaustegui Fernández se centró en el papel del personal sanitario militar de esa misma década. Los primeros estatutos orgánicos para los Territorios españoles del Golfo de Guinea, aprobados en 1858, establecían una nueva organización administrativa y colonial con disposiciones específicas sobre la salud pública en el territorio. Los numerosos informes, peticiones y solicitudes de parte de los varios gobernadores de este período son consistentes en la solicitud al Ministerio en Madrid de material médico, incremento de la financiación y recursos humanos, para la viabilidad de la colonia. Por supuesto, esto no es exclusivo de este territorio. El médico militar español Federico Montaldo y Peró, que ocupó cargos en otras posesiones coloniales insulares antes de ser destinado a África, contribuyó a través de sus ensayos a desmitificar el papel de

209 Ver también Stoler (2013), para un conjunto de estudios sobre la teorización de la ruina en el contexto colonial. 
las empresas colonizadoras, al tiempo que hacía hincapié en el papel fundamental de la salud y la higiene en los proyectos de estado: ${ }^{210}$

Todavía en los albores de este siglo, eran las tierras intertropicales el foco de que irradiaban infinitas leyendas seductoras, sin más base ni fundamento que la imaginación descarriada de viajeros indoctos, antes poetas líricos que observadores técnicos y cuyas descripciones floridas encantaban á los Gobiernos y embaucaban á las gentes, haciéndoles creer que en estas regiones intertropicales todo eran jardines deliciosos, naturaleza pródiga y eternas primaveras. De ahí nacieron, y sólo así se explican en cierto modo, esas expediciones colonizadoras, seguidas de aterradores fracasos, que sembraron de cadáveres europeos todos estos sońados paraísos é infundieron el terror en los Gobiernos $(1898,3)$.

Esta sería todavía la fase más interesada del despliegue de la llamada medicina tropical, aquella en la que los estudios científicos y las expediciones médicas, al igual que las estadísticas que se generan, toman como base las bajas entre las fuerzas militares y los miembros de la administración colonial. El objetivo prioritario de estos proyectos es preservar la salud y las vidas europeas, excepción hecha de aquellos momentos en que las epidemias, y la consiguiente escasez extrema de mano de obra local, provocaron una situación de crisis y de descontrol que pusieron en riesgo las bases del proyecto colonial en su conjunto. Fernando Poo nos provee varios de estos ejemplos. En el año 1862 se desató la primera de tres grandes epidemias consecutivas que afectaron a la isla, la de fiebre amarilla "importada de la costa africana por un pontón inglés que recaló en Santa Isabel, y que causó numerosas víctimas. Entre la dotación de los buques de la Armada hubo 41 fallecidos" (De Granda Orive, 2011, 56). En el año 1864 la epidemia de viruela, que se especuló fue traída por una compañía naviera inglesa que hacía la ruta entre Liverpool y las costas de África, se propagó con tal rapidez entre la población local, eminentemente bubi, que afectó a más de 600 personas. Sin embargo, los dispositivos sanitarios se orientaron de manera preferente hacia los miembros del Ejército y los sectores de población necesarios para el mantenimiento de los intereses coloniales. No sorprenden por tanto las reacciones locales. Varias fuentes señalan que "Los propios indígenas, motu proprio, sin consulta ni consejo facultativo, optaron, en dos periodos distintos de la epidemia, por la inoculación de la viruela tomando el pus de sujetos en que se había desarrollado

210 Fue autor de varios libros, entre ellos Guía práctica, higiénica y médica del europeo en los países tórridos. Filipinas, Cuba, Puerto Rico, Fernando Poo (1898), y Fernando Poo. Observaciones médicas e higiénicas (1898). 
de manera benigna" (De Grande Orive, 2011, 56). Pero a pesar de las medidas adoptadas, los partes médicos fueron taxativos: "En enero de 1865 se dio por extinguida la epidemia que aquejó, dentro de la población negra, a más de seiscientas personas, con el desenlace de noventa y siete muertos y respetando a la población blanca" (De Grande Orive, 2011, 56).

Crisis sanitarias como las referidas acarrean consecuencias tangibles e intangibles bastante predecibles, y son susceptibles de interpretaciones varias, incluyendo la automática asociación entre África y el supuesto 'terror' a la enfermedad, la morbilidad, y la mortandad. Es una variante del tropo clásico, dentro de la historiografía colonial, vinculado al miedo a lo desconocido en el imaginario occidental. Los conceptos de raza, contaminación y pureza habían entrado, desde el siglo XIX, en el debate sobre las enfermedades y las políticas de la salud pública en el contexto colonial africano, pero bajo la lógica racional de que un cuerpo enfermo particular era siempre el resultado de un entorno humano y geográfico inherentemente enfermo. Esta categoría de determinismo geográfico tenía su equivalente más individual y concreto en lo que señala Sean Quinlan, "en contraste con los médicos europeos de la época (que privilegiaban las diferenciaciones de clase), los médicos coloniales enfatizaron las diferencias biológicas de tipo racial" $(2005,107)$. Otro ejemplo concreto de la sistemática racialización de la medicina colonial es el de la etiología del paludismo, una de las preocupaciones más tempranas y más aterradoras de los administradores españoles y de los participantes en las expediciones tempranas. Se invocaron de manera sistemática definiciones, principios y prácticas racistas, incluida la segregación forzosa de mano de obra local. El médico militar Luis López Saccone, que en 1893 defendió su tesis doctoral titulada Apuntes medico-geográficos sobre la isla de Fernando Poo y consideraciones sobre el paludismo como enfermedad principal del pais, razonaba en uno de los capítulos, titulado "Inmunidad de las razas para el paludismo y consideraciones sobre la aclimatación" $(1893,35)$, que la enfermedad afectaba a todas las razas, pero en mayor proporción a la caucásica, para concluir: "Ninguna raza goza de inmunidad enfrente del paludismo, pero la raza negra parece poseer cierta resistencia que le permite soportar con alguna esperanza de no sucumbir, los trabajos rudos del campo y del bosque" $(1893,72)$. Estos presupuestos deterministas que tienen su base en el racismo científico, fueron asumidos y reiterados sin cuestionamiento por varios historiadores contemporáneos, lo que permite ilustrar la trascendencia de estas concepciones. Esta idea, por supuesto, permeaba los discursos biomédicos e históricos sobre África a lo largo de la primera mitad del siglo XX. El paludismo, dentro de este imaginario médico-racial, no era una enfermedad cualquiera para el administrador colonial, pues se entendía 
que en su control residía la capacidad de permitir, o impedir, el acceso mismo al continente. Reflexionando sobre sus experiencias como médico colonial en una entrevista después de la Guerra Civil Española, Nájera Ángulo recordaba (imbuido en fervor patriótico) que había sido un español quien "al descubrir la quinina, nos entregó las llaves del trópico, y particularmente de África” (1944, 302). Es indudable que algunas enfermedades obsesionaron más que otras a los administradores e inspectores de salud pública, aunque los estrategas racionalistas concebían la salud no como un fin en sí mismo, sino como un requisito previo para el desarrollo colonial.

La historia natural y las ciencias biomédicas fueron de la mano en los estudios realizados a finales del siglo XIX y primeras décadas del XX. Se trataba de una versión del higienismo y la sanidad basados en investigaciones empíricas que asociaban la salud y la geografía, generando topografías médicas que consideraban la génesis y evolución de las enfermedades como fuertemente determinadas por el clima y el medio natural. Estas topografías médicas habían tenido su origen en proyectos ilustrados de siglos anteriores y procedían de tradiciones eminentemente inglesas y francesas, pero se revitalizaron como imperativo de subsistencia ante la expansión colonial africana y acabaron por definir la relación entre espacio, enfermedad, nación y salud. Las estadísticas, la recopilación de datos meteorológicos, hidrológicos, demográficos, agrarios, etc... eran solo parte de este empirismo médico-higienista. También es de resaltar que estas topografías médicas, en el caso español, fueron siempre proyectos institucionales, promovidos por el ejército, por las corporaciones médico-científicas, por las sociedades geográficas, o por las academias, como la de medicina. De acuerdo a Luis Urteaga (1980), será la implantación plena de la bacteriología (reorientada a una concepción de la enfermedad como fenómeno puramente biológico) la que venga a revolucionar las bases de las topografías médicas, aunque éstas se siguieron produciendo hasta casi los años 40 .

Durante la fase expansionista del establecimiento de una economía de plantación, entre 1928 y 1936, la infraestructura del sistema médico colonial se consolidó de manera significativa. Los administradores se ocupaban de inaugurar hospitales, dispensarios, orfanatos, almacenes farmacéuticos, e hipnoserías, a los que le siguieron otros espacios para la segregación y el confinamiento a lo largo del territorio. En cuanto a las tecnologías biomédicas mismas, la economía extractiva que caracterizó el sistema colonial en la isla de Fernando Poo, y progresivamente se extendió al Muni, con las concesiones forestales, se reflejaba metafóricamente en una nueva práctica médica habitual, la de la extracción de 
sangre para el análisis. La extracción masiva de sangre era una práctica que se generalizó en principio entre la población masculina, que constituía la fuerza de trabajo en las plantaciones y en la industria de la madera. Es en este contexto que podemos evaluar críticamente algunas de las expediciones médicas, desde la de Gustavo Pittaluga, en 1909, cuyo objetivo fue el de llevar a cabo estudios sobre la tripanosomiasis y que produjo un gran número de estadísticas a través de análisis de sangre obligatorios. La trascendencia de estas extracciones de sangre a gran escala, más allá de su valor metonímico, fue que en una cultura colonial que implementaba progresivamente la aplicación de las políticas de salud pública, tales prácticas sirvieron para establecer nuevos puestos de control. Los análisis de sangre se convirtieron en un mecanismo de vigilancia tecnológico, hasta el punto de que un "certificado de examen de sangre" llegó a ser obligatorio para cualquiera transacción básica de la población local. Esta política de control se intensificó después de la Primera Guerra Mundial, con la imposición de un documento obligatorio, el Pasaporte sanitario, con el que se ejerció un control demográfico que incluía inspecciones de puerta a puerta, en los poblados y en los centros urbanos, desde el más cercano hasta el más remoto. Sin este documento ningún individuo podía moverse libremente de una localidad a otra, y mucho menos cruzar fronteras. Tampoco se podía emplear como bracero, firmar un contrato de trabajo, efectuar una transacción comercial, obtener licencia de caza, casarse, u obtener los permisos necesarios para construir una casa modesta. Estos pasaportes requerían una serie de sellos: "Libre de tripanosomiasis; apto para el trabajo; vacunado contra la viruela", y más tarde "Indemne de la lepra" (Ligero Morote, 1997, 136). Este documento era también, en efecto, un impuesto económico, pues tenía que validarse con un sello oficial. En un principio se requirió solamente para los adultos, pero pronto se extendió a toda la población y se impusieron multas de elevado coste por la violación de estos procedimientos, tan inasequibles para la mayoría que en muchos casos sólo podían pagarse con una pena de prisión.

Los años 1940 y 1950, marcaron un momento álgido en la proliferación de informes científicos con tablas antropométricas (peso, altura, tamaño, tórax, ángulo de visión, destreza, memoria,...) y, como novedad, las pruebas de psicología infantil, con aplicaciones específicas a la pedagogía y el desempeño laboral. Estas pruebas de inteligencia se realizaron de forma generalizada en las escuelas y orfanatos de la colonia. Publicaciones como El niño guineano: estudio antropométrico y psicotécnico del niño negro (1956) realizado por el director de una escuela colonial, Jesús de la Serna y Burgaleta, u otro de 1952, ampliamente referenciado por su título inflamatorio, Capacidad mental del negro, publicado por Vicente 
Beato y Ramón Villarino, formaban parte de un cuerpo muy racializado de bio-conocimiento colonial, cuya intención era la de proporcionar los medios adecuados de intervención educativa en uno de los sectores más vulnerables de la población, los niños. Estas pruebas, que el sistema colonial español había apropiado y adaptado a sus proyectos de colonización, se habían formulado con anterioridad a la Segunda Guerra Mundial por psicólogos como Robert Yerkes y Alfred Binet. Pero en Guinea se aplicaron (si bien tardíamente, en comparación a otras colonias vecinas) no sólo a los niños, sino también a los profesores, trabajadores de la administración pública, miembros de la guardia colonial y otros sujetos subalternos.

Un locus particularmente distintivo dentro la topografía de la represión colonial biomédica y del confinamiento es el que constituyó la colonia de leprosos de Mikomeseng, creada en los años 30 e inaugurada oficialmente en $1945 .{ }^{211}$ Mikomeseng, cerca de la frontera con Camerún y a pesar de estar en el interior y no en la costa, puede definirse como una especie de isla institucional, o lo que Ann Laura Stoler ha denominado un "archipiélago carcelario del imperio" $(2008,203)$. Fue para la administración colonial de la salud pública casi una colonia dentro de otra colonia, pues ofreció la posibilidad de fundar una nueva comunidad local, un espacio de bioingeniería según los valores y categorías de la metrópolis. ${ }^{212} \mathrm{El}$ recinto de Mikomeseng, que tenía aspecto de fortaleza, incluía un hospital (con sala de cirugía y pabellón de maternidad); una clínica para el tratamiento diario y para las revisiones médicas; filas de casas para los internos; una casa central para los médicos españoles, enfermeras y administradores; una iglesia; y un área para el cultivo, ya que se concibió como asentamiento agrícola, aprovechando la mano de obra obligatoria de los enfermos. La parte más temida de todas dentro de este complejo fue la unidad de aislamiento. El recinto se organizaba bajo el modelo de un mini-estado semi-independiente, auto-controlado y totalitario, con su propia moneda de metal, Reglamento y autoridades médicas. Cada hora del día, el trabajo y las relaciones familiares estaban controlados; la vida y la muerte en mano de los responsables del recinto. La guardia colonial patrullaba las murallas, el destacamento militar estaba solo a la vuelta de la

211 La Misión Especial de Endemias comenzó en 1933, y llevó a los poblados de segregación de leprosos, el primero de los cuales es el que estableció J. Chacón en Ebibeyín (Martínez, 1954).

212 Según Megan Vaughan, "La colonia de leprosos, al igual que otras instituciones coloniales, era un lugar de una compleja organización social, regido por un número de ideas médicas, religiosas y sociales convergentes" (1991, 83). 
esquina del complejo. Para los confinados en el interior, el espacio les aseguraba un aislamiento total del mundo exterior.

En el año 1946 una instalación adicional se añadió al complejo de la leprosería en Mikomeseng: la llamada Casa-cuna, operado bajo los criterios de un orfanato aunque, en sentido estricto, no se contempló para los huérfanos sino para los hijos de los pacientes leprosos. Gestionado exclusivamente por monjas de los servicios de salud, estas instituciones revelaron las dimensiones represivas de la política de confinamiento aplicadas a la infancia. Todos los bebés nacidos de pacientes de la colonia eran forzosamente alejados de sus madres al nacer, para criarse como huérfanos en estos centros, o dados a familias de acogida después de la edad de cinco ańos. Esta fue una de varias maneras en que el sistema de salud, con la ayuda de la Iglesia, ejerció su poder sobre el cuerpo de la mujer, mediante el control de la natalidad. Por supuesto, el director del centro en Mikomeseng, el médico Martínez Domínguez, admitía que, "esconder a los niños y la fuga de las mujeres embarazadas para evitar la separación era bastante frecuente" (Martínez, 1954, 42). Uno de los daños colaterales más trágicos de estas políticas agresivas fue que la tasa de mortalidad infantil en los orfanatos era alarmante, llegando a alcanzar el 70\% (Martínez, 42), mientras que la tasa de mortalidad de los niños criados directamente por sus padres leprosos era, al menos, cinco veces inferior. Las explicaciones oficiales fueron siempre esquivas y concisas, achacando la mortalidad a "la incapacidad de los nińos negros criados en orfanatos para tolerar la fórmula para bebés” (Martínez, 1954, 42-43).

El cuerpo arruinado del leproso podría definirse como un icono crítico de la intervención colonial. "El cuerpo enfermo se convirtió en el significante ultimo no sólo del entorno patológico, sino de la falta total de auto-control físico ejercido por el individuo europeo sobre el individuo colonizado" (Ballantyne y Burton, 2005, 120). Esta influencia se extendía a la capacidad del individuo para desarrollar relaciones familiares, modos de paternidad o de maternidad, relaciones étnicas y comunitarias. El cuerpo del leproso, como símbolo de la ruina, contiene un importante tráfico de significado, y puede ser reformulado, bajo esta categoría de la ruina, como una instancia dentro de una historia más amplia de implementaciones de tecnología biomédica. El simbolismo de la ruina, como alegoría del cuerpo desmembrado, resurge en la categorización y tratamiento-colonial y administrativo- del cuerpo enfermo; es un tropo poderoso que condensa imágenes y significado. La mayoría de los tratados sobre la lepra, así como de otras enfermedades de patente deformación física, semejan un catálogo de horrores médico-tropicales: a menudo incluyen colecciones fotográficas de 
las enfermedades más inhumanas a página completa, desde la elefantiasis del escroto hasta casos avanzados de lepra. A veces se proporciona la imagen antes y después, o durante las varias fases, del tratamiento, a modo de evidencia del éxito profesional del sistema. Exponen el empirismo implacable de principios médicos y la obsesión por la catalogación del territorio, sus pueblos y sus individuos, pero los sujetos de estudio son seres anónimos, sin nombre, sin expresión: son una objetivación científica bajo cuyo retrato solemos leer un párrafo descriptivo con las estadísticas, biometría y verborrea farmacéutica. Estas colecciones fotográficas de fragmentos corporales anónimos (extremidades, partes de rostros, o rostros completos, desde diferentes ángulos) se describen de la siguiente manera:

Fotografía número uno: "Tratamiento desde enero de 1950 hasta septiembre de 1952 (Sulphetrone, 896 pastillas de 0.5 gramos; Diasone, 152 pastillas de 0.3 gramos)";

Fotografía número dos... (Martínez Domínguez, 1954).

La complejidad de la relación entre la imagen y el colonialismo hace difícil no sólo mostrar, sino incluso describir estos archivos de enfermedades, deformidades corporales y otras representaciones de la ruina humana tal y como aparecen en estos textos científicos y pseudocientíficos coloniales. Como nos advierte Nancy Rose Hunt (2013) no debemos caer en la trampa de repetir ni de reproducir la tenacidad de lo visual, ni el sentido de choque que infligen estas imágenes. El cuerpo se convierte en una oportunidad para la reflexión taxonómica. Lo visual y lo ostensiblemente "científico" se complementan entre sí, con la ayuda de la fotografía. En definitiva, los cuerpos y las mentes de los sujetos colonizados fueron motivo de preocupación, de escrutinio, de ansiedad y de vigilancia en la arquitectura colonial de la salud en los Territorios españoles del Golfo de Guinea. Recibieron y mantuvieron "la atención de los funcionarios coloniales en maneras que demuestran lo fundamental que se consideraba su gestión para el orden social y para la estabilidad política" (Ballantyne y Burton, 2005, 5). Atentos a "los lugares inesperados en los que el estado colonial ha dejado sus huellas (...) y en los que las desigualdades del presente se hacen palpables" (Stoler, 2013, 3), esta reapropiación del aparato biomédico colonial sirve a su vez para problematizar cuestiones de duración, de reproducción y de repetición en los regímenes dictatoriales del presente. Las inmensas desigualdades sociales y económicas que el sistema político y clientelar sigue generando y promoviendo suscitan nuevamente preguntas sobre la leprosería de Mikomeseng, los orfanatos, las hipnoserías, las casas-cuna y tantas otras instalaciones sanitarias, ahora decrépitas, a lo largo de 
la geografía nacional. ¿Bajo qué condiciones se han dejado arruinar estos lugares, se han resignificado, o han quedado abandonados a su suerte? Algunas de estas ruinas se ignoran, como inocuos restos del pasado, otras se resisten a desaparecer, se rehabilitan o simplemente se habitan, para cumplir con una agenda política en el presente.

Esto nos lleva a una breve referencia a la situación socio-política actual. En abril del año 2015 se detuvo en la capital del país a Andrés Esono Ondo, líder del partido de la oposición CPDS, bajo acusaciones de que este partido había "comprado"-literalmente-un paciente de ébola en Guinea Conakry. El régimen lo acusa de haber traído el paciente a Guinea con el fin de propagar la enfermedad, y con la intención de desestabilizar el poder político y crear un estado de terror social. Nuevamente, en este episodio tan anecdótico como anodino, la salud pública y el miedo se fusionan en una misma categoría, al tiempo que actúa como estrategia de represión política y social. La patología sistémica de las dictaduras encarna, como parte de su etiología, manifestaciones clínicas que incluyen la obstrucción de los valores democráticos y la propagación de un sistema clientelar que convierte en endémicas las desigualdades sociales y económicas. Esta patología del poder se desarrolla con más virulencia en un clima de perpetua intimidación, en el que una alianza forzada con el partido en el poder es a veces un modo de supervivencia, y en el que la transmisión vertical de la autoridad facilita la efectividad del contagio. Al final, el propio líder puede llegar a ser un mero instrumento, un nexo en la dinámica social de esta patología. En Guinea Ecuatorial la corrupción es sintomática y es sistémica, la explotación sin escrúpulos de los recursos del país por la cúpula en el poder es febril y es viral. En este clima político, las ostensibles (aún si anodinas) preocupaciones por la salud pública siguen utilizándose como pretexto para la represión política, para la persecución, y para el aplastamiento brutal de las libertades fundamentales. 


\section{Bibliografía}

ANDERSON, W. (1998). "Where is the postcolonial history of medicine?”. Bull. Hist. Med., 72, 522-530.

BALLANTYNE, Tony y Burton, Antoinette, eds., (2005). Bodies in contact. Rethinking colonial encounters in world history. Durham: Duke University Press.

BELAUSTEGUI Fernández, Alejandro (2013). Sanitarios militares en Guinea Ecuatorial. 1858-1868. Madrid: Centro de Publicaciones del Ministerio de Defensa.

DE GRANDA Orive, J. (2011). "Sanidad Militar y aspectos sanitarios en Fernando Poo durante el gobierno de los brigadieres (1859-1869)" Sanidad Militar, 67, 1, 53-60.

FANON, Franz (1978). "Medicine and Colonialism", en J. Ehrenreich, ed., The cultural crisis of modern medicine. New York: Monthly Review Press, 229-251.

FERRER Piera, Pablo (1900). Fernando Poo y sus dependencias. Descripción, producciones y estado sanitario. Barcelona: A. López Robert, Impresor.

HUNT, Nancy Rose (2013). "An acoustic register. Rape and repetition in Congo". Ann Laura Stoler, ed. Imperial debris. On ruins and ruination. Durham: Duke University Press, 39-66.

LANDAU, Paul S. y Kaspin, Deborah, eds. (2003). Images and empires. Visuality in colonial and postcolonial Africa. University of California Press.

LIGERO Morote, Armando (1997). La sanidad en Guinea Ecuatorial, 1778-1968. Jaén: edición del autor.

MARKS, Shula (1997). "What is colonial about colonial medicine? And what has happened to imperialism and health?". The Society for the Social History of Medicine, 10, 2, 205-219.

MARTÍNEZ Antonio, Francisco Javier (2009). "Imperio enfermizo. La singular mirada mórbida del primer franquismo en los documentales médicos sobre Marruecos y Guinea”, Medicina e historia. Revista de estudios históricos de las ciencias médicas, $4,1-16$.

MARTÍNEZ Domínguez, Víctor (1954). Estudio epidemiológico y clínico de la epidemia de lepra en la Guinea Española. Madrid: Consejo Superior de Investigaciones Científicas.

MAYER, Ruth (2002). Artificial africas. Colonial images in the times of globalization. Hanover and London: University Press of New England.

MEDINA Doménech, Rosa María y Molero Mesa, Jorge (2002). "La ley sanitaria colonial. Marco legislativo para el análisis de la medicina colonial española en África”, en Díez Torre, Alejandro R. ed., Ciencia y memoria de África. Actas de las III 
jornadas sobre 'Expediciones científicas y africanismo español. 1898-1998'. Alcalá de Henares: Universidad de Alcalá de Henares.

MEDINA Doménech, Rosa María (2003). "Desconocimiento y desidia en la interpretación colonial de la morbilidad palúdica”, en Rodríguez Ocaña, Esteban, ed. La acción médico-social contra el paludismo en la España metropolitana y colonial del siglo XX. Madrid: Consejo Superior de Investigaciones Científicas, 383-427.

MONTALDO y Peró, Federico (1898). Guía práctica, higiénica y médica del europeo en los paises tórridos. Filipinas, Cuba, Puerto Rico, Fernando Poo. Madrid: Imp. de Ricardo Rojas.

(1898). Fernando Poo. Observaciones médicas e higiénicas. Madrid: Celestino Apaolaza Imp.

MORTON, Adam David (2005). “The 'failed state' of international relations", New Political Economy, 10, 3 (septiembre), 371-379.

NÁJERA Ángulo, Luis (1931). "El factor sanitario y las explotaciones forestales en la Guinea espańola", Montes e industrias, 3, (enero), 15-18.

(1932). Los territorios españoles en el Golfo de Guinea. Estado sanitario actual y su influencia sobre el desarrollo de la colonización. Madrid: Impr. del P. de H. de Intendencia e Intervención Militares.

(1932). "Expediente incoado para esclarecer las denuncias formuladas por D. Luis Nájera y D. Higinio París, Presidente y Secretario de la asociación de médicos coloniales, sobre la situación de los servicios sanitarios en los territorios españoles del Golfo de Guinea", Archivo General de la Administración, África, Sección 15, Fondo 4, Caja 81-06336.

(1944). "La sanidad pública y la colonización africana", Revista de sanidad e higiene pública, 18, 299-304.

(1944). "El paludismo náutico", Revista Ibérica de Parasitología, IV, 3, 343-355.

NÅJERA Morrondo, Rafael (2006). "El Instituto de salud Carlos III y la sanidad espańola. Origen de la medicina de laboratorio, de los institutos de salud pública y de la investigación sanitaria", Revista española de salud pública, 5, septiembre-octubre, 585-604.

NERÍN, Gustau (2010). La última selva de España. Antropófagos, misioneros y guardias civiles. Madrid: La catarata.

QUINLAN, Sean (2005). "Colonial bodies, hygiene, and abolitionist politics in eighteenth-century France", en Tony Ballantyne y Antoinette Burton, eds., Bodies in contact. Rethinking colonial encounters in world history. Durham: Duke University Press. 
ROBERTS, Andrew (2013). "Salisbury, the empire builder who never was", History Today, 49, 10, sin página. Disponible en: http://www.historytoday.com/andrewroberts/salisbury-empire-builder-who-never-was

STEHRENBERGER, Cécile Stephanie (2014). "Medicina colonial y literatura franquista: el caso de las novelas de Liberata Masoliver", Revista Debats, 123, 2, 48-57.

STOLER, Ann Laura (2008). "Imperial debris: reflections on ruins and ruination", Cultural Anthropology, 23, 2, 191-219.

(2013). Imperial debris. On ruins and ruination. Durham: Duke University Press.

STORM, Eric (2004). "The problems of the Spanish nation-building process around 1900", National Identities, 6. 2 (julio), 143-157.

URTEAGA, Luis (1980). "El higienismo en España en el siglo XIX y el paradigma de las topografías médicas". Tesis doctoral, Universidad de Barcelona.

VAUGHAN, Megan (1991). Curing their ills. Colonial power and African illness. Stanford: Stanford University Press. 